\title{
Child Neurology: Hypotonia and Delayed Teeth Eruption in a 2-Year-Old Girl
}

Darina Dinov, DO, Gregory Vorona, MD, and Amy Harper, MD

Neurology ${ }^{\circledR}$ 2021;97:875-878. doi:10.1212/WNL.0000000000012445
Correspondence

Dr. Dinov

darina.dinov@vcuhealth.org

\begin{abstract}
POLR3-related disorders are rare hypomyelinating leukodystrophies associated with hypodontia. We present a female patient, who was referred to pediatric neurology at 2 years of age for tremor, low tone, and motor delays. In addition, she was noted to have a delay in her teeth eruption and myopia. Neurologic examination was significant for ataxic features and global developmental delay. Laboratory workup was unrevealing. MRI was significant for hypomyelination. Genetic testing confirmed a pathogenic variant of POLR3B. POLR3related leukodystrophies should be considered in patients who present with hypotonia, ataxia, and hypodontia. There are many different subtypes of POLR-related leukodystrophies each with distinguishing phenotypic and radiographic features. Although MRI can be helpful in initial evaluation, genetic testing is needed for confirmatory diagnosis and to guide prognosis.
\end{abstract}

\section{Case Presentation}

We present a female patient, who was referred to pediatric neurology at 2 years of age for tremor and motor delays. A review of early milestones reveals that she was able to sit at 6 months, crawled at 9 months, and was cruising by 12 months of age. By 2 years of age, fine motor and language delays as well as a prominent tremor were apparent. She has had intermittent followup to 5 years of age. With the help of therapy, she has continued to progress gaining the ability to stand for less than 5 seconds and to ambulate with a walker. She never developed independent walking, and her language remained delayed. There has been no developmental regression reported to date.

Her medical history was essentially benign. She was the product of a term uncomplicated pregnancy and delivery with a birth weight of $2.86 \mathrm{~kg}$. Medical history was significant for low muscle tone and motor delay noted on evaluations by physiatry and orthopedics. X-rays of the hips were negative for hip dysplasia. Of interest, she did have a delay in her teeth eruption. An ophthalmology assessment revealed myopia but no cataracts, nystagmus, or optic nerve abnormalities.

Her initial neurology examination was notable for low muscle tone, global developmental delays, and ataxic features including dysmetria and truncal titubations. Functionally, she was able to generate good strength, had no sensory deficits, and displayed intact reflexes. There were no cranial nerve abnormalities. Examination findings prompted several investigations. Laboratory studies included CPK, free T4, TSH, free and total carnitine levels, acylcarnitine profile, very-long-chain fatty acids, lysosomal enzymes, karyotype, and microarray, which were all unrevealing. Initial lactate was elevated at $2.8 \mathrm{mmol} / \mathrm{L}$, but the repeat was in a normal range.

An EEG was performed and showed slowing, disorganization, and mild bihemispheric dysfunction; however, no epileptiform discharges were noted. Further evaluation at age 2 years included a brain MRI that revealed an abnormal pattern of myelination for the 
patient's age. There was a marked paucity of ageappropriate cerebral white matter T2 signal intensity with small areas of T2 signal hypointensity-visualized within the posterior limbs of the internal capsules, within the ventrolateral thalami, and along the optic radiations (figure, A). There was also limited normal age-appropriate cerebral white matter $\mathrm{T} 1$ signal hyperintensity, particularly within the frontal lobes (figure, B). Posterior fossa abnormalities were present, which included delayed cerebellar myelination (figure, C) and vermian atrophy that disproportionately affected the anterior aspect (figure, D). At this time, genetic testing (duplication/deletion and sequencing) was initiated because of the concern for a hypomyelinating leukodystrophy. This included POLR3A gene testing, which was negative. She was referred to a leukodystrophy specialist who pursued $P O L R 3 B$ and POLR1C testing, revealing a pathogenic variant in POLR3B.

A follow-up visit was conducted at age 5 years. At that time, she was receiving occupational, physical, and speech therapy.
She showed advancements in her skills with the ability to walk with a walker for a few steps, speak in 3- to 4-word sentences, feed herself, and assist in dressing. Based on her subtype prognosis, some continued improvement in her language and motor skills would be expected. Although most leukodystrophies manifest as progressive disorders, the clinical course of patients with RNA polymerase III (POLR3)-related leukodystrophies can vary. ${ }^{1}$ The exact reason for this variability is unclear. Currently, it is postulated that genetics and age at onset play a role. Most patients diagnosed as infants show some improvement but ultimately do not have the ageappropriate characteristics. ${ }^{1}$

\section{Discussion}

Early recognition of a concise pattern in analyzing hypotonic patients is essential. In evaluating hypotonia, there are 5 main groupings to consider: (1) CNS, (2) lower motor neuron, (3) nerve, (4) neuromuscular junction, and (5) muscle. ${ }^{2}$ Within these categories, a pattern of global developmental delay is most likely "central" hypotonia, localized to the brain. Initial

Figure MRI T1 and T2 Images
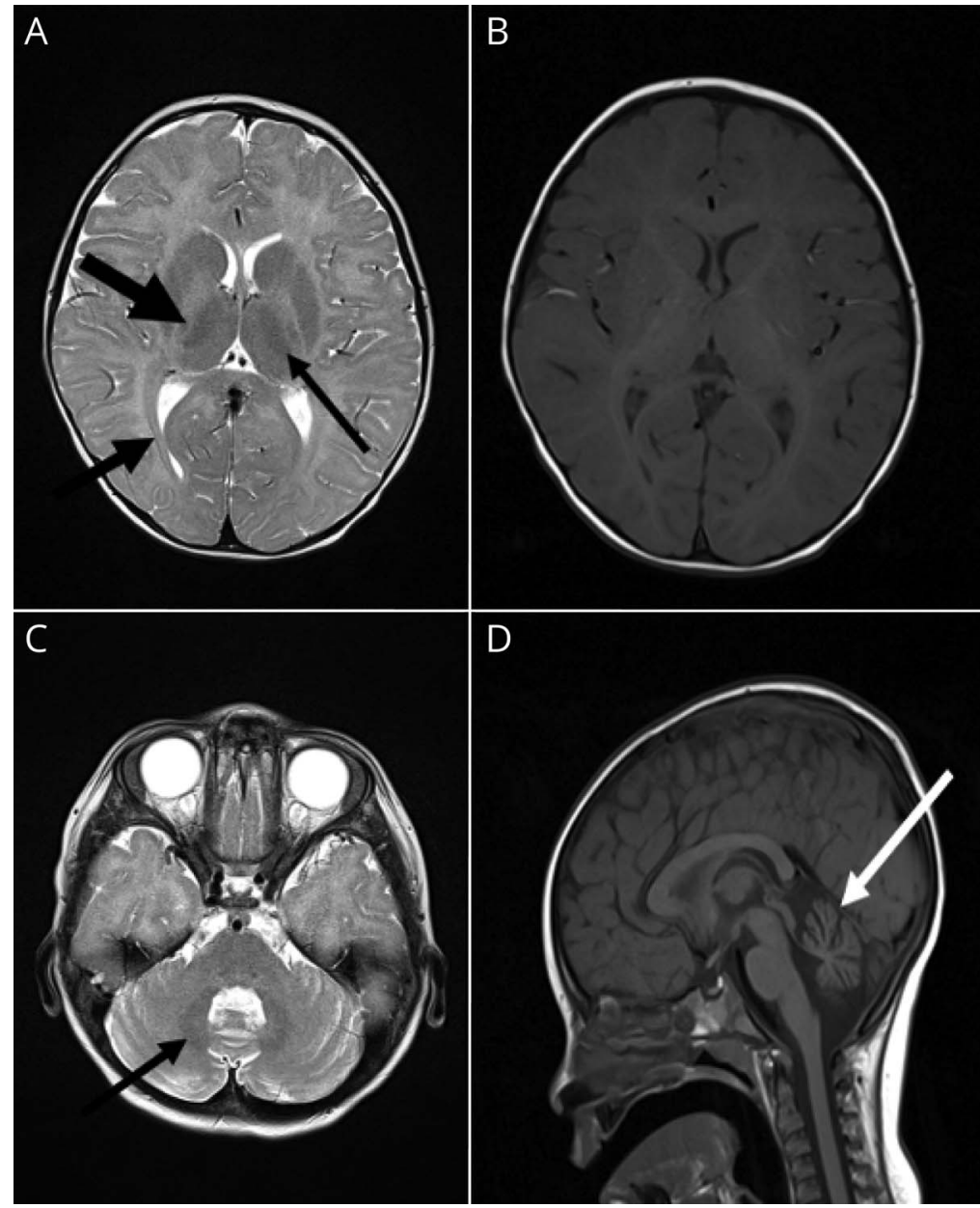

(A) T2 hypointensity in the posterior limb of the internal capsule (thickest arrow), along the optic radiations (middle thickness arrow), and within the ventrolateral thalamus (thinnest arrow); (B) diffuse T1 hypointensity particularly in the frontal lobes; (C) T2 hypointensity in the hila of the cerebellar nuclei (black arrow), with absent normal white matter T2 signal hypointensity within the remainder of the cerebellum including the middle cerebellar peduncles; and (D) T1 vermian hypoplasia disproportionately affecting the anterior aspect (white arrow). 
evaluation of a patient presenting with hypotonia should include a thorough history-including prenatal history, delivery, development, and physical examination. Workup to further guide diagnosis includes $\mathrm{CPK}, \mathrm{CBC}, \mathrm{CMP}$, and thyroid testing. If a central etiology is suspected, a brain MRI should be obtained. ${ }^{3}$ Screening metabolic evaluations may include a lactate, ammonia, serum amino acid profile, urine organic acids, and acylcarnitine profile, as well as free and total carnitine level. If there is evidence to support a possible leukodystrophy based on neuroimaging and clinical features, such as in this case, additional laboratory studies include very-long-chain fatty acids, lysosomal enzymes, and specific gene testing.

Although $P O L R 3 B$ is a rare neurologic presentation in patients, it is an important consideration in a pediatric patient who presents with hypotonia and hypodontia. Overall, the main presenting symptoms specific for POLR $3 B$ are ocular abnormalities, abnormal dentition, endocrine abnormalities, and neurologic features. ${ }^{4}$ Ocular abnormalities most commonly present as myopia; however, strabismus has also been noted in some patients. ${ }^{4}$ Abnormal dentition is a key finding within the diagnosis because of its uniqueness. In one review, the authors found in POLR3B patients that about $70 \%$ had dental abnormalities, with the most common feature being delayed dentition. ${ }^{5}$ Other sources report dental abnormalities occurring in up to $87 \%$ of patients. ${ }^{1}$ Dental abnormalities can include neonatal teeth, hypodontia, or even abnormal tooth shape. ${ }^{4}$ Endocrine abnormalities most commonly present as short stature, which is found in $50 \%$ of patients, but can also present as hypogonadotropic hypogonadism. ${ }^{4,5}$ Neurologic symptoms most commonly present with ataxia, hypotonia, tremor, or motor delay. ${ }^{4}$

When evaluating possible POLR3-related leukodystrophy patients, it is important to identify the most prominent associated features as subtypes vary. Most POLR3-related patients present with hypomyelination, excluding this as a distinguishing feature. Patients who present with predominantly endocrine abnormalities such as hypogonadotropic hypogonadism will most likely have hypomyelination, hypodontia, and hypogonadotropic hypogonadism (4H syndrome). ${ }^{4}$ Dental abnormalities with the absence of endocrine involvement suggest either the ataxia, delayed dentition, and hypomyelination $(\mathrm{ADDH})$ or leukodystrophy with oligodontia (LO) subtypes. ${ }^{4}$ The presence of neurologic features further differentiates these subtypes. Patients with $\mathrm{ADDH}$ present with ataxia, whereas patients with LO do not have predominant neurologic signs. ${ }^{4}$ In addition, $\mathrm{ADDH}$ presents with delayed dentition, whereas LO is a leukodystrophy with oligodontia. ${ }^{4}$ In patients with mainly neurologic symptoms, MRI is important to distinguish between tremor-ataxia with central hypomyelination (TACH) and hypomyelination with cerebellar atrophy and hypoplasia of the corpus callosum (HCAHC) subtypes. ${ }^{4}$

Our patient presented with delayed teeth eruption, hypotonia, developmental delay, and ataxic features, which prompted the concern for a POLR3-related leukodystrophy. These autosomal recessively inherited disorders are associated with changes in the POLR3A, POLR3B, and POLR1C genes. Genetic testing in this patient confirmed 2 pathogenic POLR3B variants. Based on her presentation, $4 \mathrm{H}$ would be unlikely given the absence of endocrine findings. Her dental abnormalities suggest either the ADDH or LO subtype. The presence of ataxia and tremor supports $\mathrm{ADDH}$ as the more likely subtype. In POLR3-related leukodystrophy disorders, clinical and radiographic features identify the subtype. Among the genes, the phenotypic overlap exists, but prognosis varies with POLR3B having the best outcome. Although patients with $P O L R 3 B$ present earlier, they have a slower disease manifestation compared with POLR $3 A^{4}$

When a POLR3-related disorder is considered, the main diagnostic study other than genetic testing is a brain MRI that demonstrates hypomyelination (figure. B). In the interpretation of pediatric MRIs, it is imperative to consider the myelination timeline. There is an expected pattern of myelination on MRI, with structures appearing myelinated earlier on T1-weighted imaging compared with T2-weighted imaging. In general, T1-weighted imaging after approximately 10 months of age does not vary, and T2-weighted imaging stabilizes after approximately $24-26$ months of age. ${ }^{6}$ With the case presented, the MRI was performed after 2 years of age and clearly presented the hypomyelination.

The utilization of MRI in the evaluation of developmentally delayed hypotonic infants more readily identifies the hypomyelination that can be associated with this type of leukodystrophy.

POLR3B hypomyelination commonly presents as hypointensities of the optic radiations, thalami, pallida, and posterior limb of the internal capsule ${ }^{4}$ as seen in our patient in figure, A. Thalamus and pallidae hypomyelination cause the delay in motor signals and ultimately the movement dysregulation (tremor) as seen in our patient. Patients may have cerebellar atrophy usually of the vermis (figure, D) and hypointensity of the dentate nuclei (figure, C) correlating with the ataxic features notable in POLR3B leukodystrophy. Appropriate correlation of clinical and MRI findings can direct the differential for centrally mediated pediatric hypotonia associated with global delays. When a hypomyelinating leukodystrophy is suspected, confirmatory genetic testing is required. There are multiple genes responsible for the POLR3-related leukodystrophies, and identification of a specific gene will best guide prognosis.

\section{Study Funding}

The authors report no targeted funding.

\section{Disclosure}

D. Dinov reports no disclosures relevant to the manuscript; A. Harper reports no disclosures relevant to the manuscript; and G. Vorona reports no disclosures relevant to the manuscript. Go to Neurology.org/N for full disclosures. 
Appendix Authors

\begin{tabular}{lll}
\hline Name & Location & Contribution \\
\hline $\begin{array}{l}\text { Darina } \\
\text { Dinov, } \\
\text { Do }\end{array}$ & $\begin{array}{l}\text { Children's Hospital of } \\
\text { Richmond, Virginia } \\
\text { Commonwealth University } \\
\text { Medical Center }\end{array}$ & $\begin{array}{l}\text { Acquired the data; analyzed } \\
\text { the data; interpreted the data; } \\
\text { and drafted the manuscript }\end{array}$ \\
\hline $\begin{array}{l}\text { Gregory } \\
\text { Morona, } \\
\text { MD }\end{array}$ & $\begin{array}{l}\text { Virginia Commonwealth } \\
\text { University Medical Center }\end{array}$ & $\begin{array}{l}\text { Acquired the data; analyzed } \\
\text { the data; interpreted the data; } \\
\text { and revised the manuscript } \\
\text { for intellectual content }\end{array}$ \\
$\begin{array}{l}\text { Amy } \\
\text { Harper, } \\
\text { MD }\end{array}$ & $\begin{array}{l}\text { Children's Hospital of } \\
\text { Cichmond, Virginia }\end{array}$ & $\begin{array}{l}\text { Acquired the data; analyzed } \\
\text { the data; interpreted the data; } \\
\text { and revised the manuscript } \\
\text { for intellectual content }\end{array}$ \\
& Medical Center &
\end{tabular}

\section{References}

1. Wolf NI, Vanderver A, van Spaendonk RM, et al. Clinical spectrum of $4 \mathrm{H}$ leukodystrophy caused by POLR3A and POLR3B mutations. Neurology 2014;83(21): 1898-1905.

2. Leyenaar J, Camfield P, Camfield C. A schematic approach to hypotonia in infancy. Paediatric Child Health 2005;10(7):397-400.

3. Shevell M, Ashwal S, Donley D, et al. Practice parameter: evaluation of the child with global developmental delay: report of the Quality Standards Subcommittee of the American Academy of Neurology and The Practice Committee of the Child Neurology Society. Neurology 2003; 60(3):367-380.

4. Bernard G, Vanderver A. POLR3-Related Leukodystrophy. GeneReviews. 2012. Available at: ncbi.nlm.nih.gov/books/NBK99167/. Accessed January 29, 2020.

5. Gauqelin L, Cayami F, Sztriga L, et al. Clinical Spectrum of POLR3-related leukodystrophy caused by biallelic POLR1C pathogenic variants. Neurol Genet 2019;5(6): e369.

6. Barkovich M, Barkovich A. MR imaging of normal brain development. Neuroimaging Clin N Am 2019;29(3):325-337.

\section{Call for Biostatisticians to peer review for Neurology ${ }^{\circledast}$}

We are seeking qualified experts to review the biostatistical aspects of submitted articles. We welcome those specializing in biostatistics with a background in experimental design and the review of randomized clinical trials, observational studies, genetic studies, and imaging studies in the neurodegenerative diseases.

If interested, please send CV to the Neurology Editorial Office: journal@neurology.org.

\section{Sign Up for the AAN's Axon Registry}

The AAN encourages its US members to show their interest in participating in the Axon Registry ${ }^{\circledR}$ by signing up today.

Use the Axon Registry to:

- Simplify reporting requirements under MACRA's Quality Payment Program and avoid penalties while reducing your administrative burden

- Meet your MOC Part IV requirements and waive up to eight credits of Part II Self-Assessment

- Choose from 22 AAN neurology-specific quality measures that fit your practice

- Use data to understand your practice and identify where improvements can be made to patient care

- Manage your patients at a population level; look at a specific group of patients based on conditions, risk factors, demographics or outcome

- Demonstrate your value to payers when negotiating reimbursement

- Enjoy multi-year, fee-free access when you sign the agreements and integrate your EHR with the registry

Learn more at AAN.com/view/Axon and send your questions to registry@aan.com. 


\section{Neurology}

\section{Child Neurology: Hypotonia and Delayed Teeth Eruption in a 2-Year-Old Girl}

Darina Dinov, Gregory Vorona and Amy Harper

Neurology 2021;97;875-878 Published Online before print June 29, 2021

DOI 10.1212/WNL.0000000000012445

This information is current as of June 29, 2021

\section{Updated Information \&} Services

\section{References}

Subspecialty Collections

Permissions \& Licensing

Reprints including high resolution figures, can be found at: http://n.neurology.org/content/97/18/875.full

This article cites 5 articles, 2 of which you can access for free at: http://n.neurology.org/content/97/18/875.full\#ref-list-1

This article, along with others on similar topics, appears in the following collection(s):

All Neuromuscular Disease

http://n.neurology.org/cgi/collection/all_neuromuscular_disease All Pediatric

http://n.neurology.org/cgi/collection/all_pediatric

Clinical neurology examination

http://n.neurology.org/cgi/collection/clinical_neurology_examination MRI

http://n.neurology.org/cgi/collection/mri

Information about reproducing this article in parts (figures,tables) or in its entirety can be found online at:

http://www.neurology.org/about/about_the_journal\#permissions

Information about ordering reprints can be found online:

http://n.neurology.org/subscribers/advertise

Neurology ${ }^{\circledR}$ is the official journal of the American Academy of Neurology. Published continuously since 1951, it is now a weekly with 48 issues per year. Copyright () 2021 American Academy of Neurology. All rights reserved. Print ISSN: 0028-3878. Online ISSN: 1526-632X.

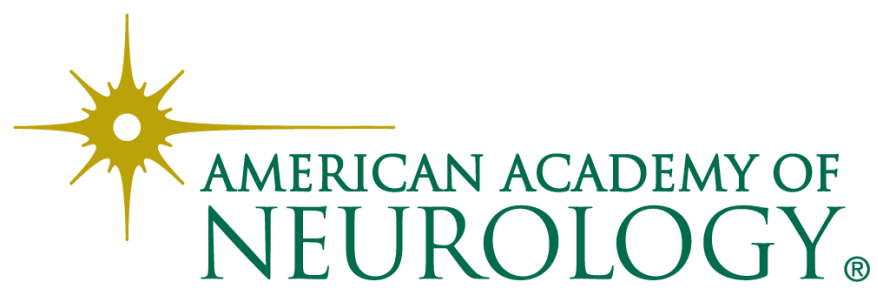

